\title{
Evaluasi Faktor-Faktor Yang Mempengaruhi Performa Implementasi SAP ERP Di Industri Retail
}

\author{
Syaiful Bakhri \\ Universitas Islam Negeri Walisongo wemarang \\ syaifulbakhri@walisongo.ac.id
}

\begin{abstract}
This study aims to examine the factors that affect the performance of the ERP implementation. These factors are: the data migration, system documentation, knowledge transfer, system testing, and integration interfaces. These factors can increase the performance of the implementation of ERP software applications that are on retail industry. The case study method in this research is using interviews and direct observation, the object of the interview in this study is Functional modules of SAP ERP. Sources of data derived from primary data and secondary data. The results of this study indicate that factors influence on the performance of retail industry. Therefore, the factors to be considered in order to improve the success of SAP ERP project in the future. The theoretical implications and suggestions for future research are also discussed in the final part of this study. (SB)
\end{abstract}

Keywords : SAP ERP, Performance Implementation SAP ERP

\begin{abstract}
Abstrak
Penelitian ini bertujuan untuk menguji faktor-faktor yang mempengaruhi performa implementasi ERP. Faktor- faktor tersebut adalah : data migrasi, dokumentasi sistem, transfer pengetahuan, pengujian sistem, dan integrasi interface. Faktorfaktor ini dapat meningkatkan performa implementasi aplikasi software ERP yang terdapat di perusahaan retail. Metode studi kasus pada penelitian ini adalah menggunakan metode wawancara dan observasi lapangan secara langsung, obyek wawancara pada penelitian ini adalah Functional modul SAP ERP. Sumber data diperoleh dari data primer maupun data sekunder. Hasil penelitian ini menunjukan bahwa faktor-faktor tersebut mempunyai pengaruh terhadap performa implementasi di industri retail. Oleh karena itu faktor-faktor tersebut agar diperhatikan sehingga dapat meningkatkan keberhasilan proyek SAP ERP di masa yang akan datang. Implikasi teoritis dan saran-saran bagi penelitian mendatang juga diuraikan pada bagian akhir penelitian ini.(SB)
\end{abstract}

Kata Kunci : SAP ERP, Performa Implementasi SAP ERP

ISSN 2715-0143 (online) ISSN 2714-9048 (print)

http://journal.walisongo.ac.id/index.php/jit/index

WJIT : Walisongo Journal of Information Technology - Vol.1 No. 2 (2019) 


\section{PENDAHULUAN}

\section{Bloor Research}

menunjukan bahwa tingkat keberhasilan suatu proyek yang tepat waktu dan sesuai anggaran sangat rendah yaitu hanya $16 \%$. Sedangkan Project Management Survey Report KPMG (2013) menyatakan bahwa proyek yang tepat waktu adalah $29 \%$ dan proyek yang sesuai anggaran adalah 33\%. Didukung dengan hasil survei yang dilakukan oleh Panorama Consulting (2016) pada Report on ERP Systems and Enterprise Software menyatakan bahwa proyek ERP yang melebihi anggaran adalah 57\%, sesuai anggaran $26 \%$, sedangkan sesuai jadwal 39\% dan dibawah jadwal $4 \%$.

Perusahaan pengguna SAP ERP di Tangerang Selatan, sejauh ini berbagai proyek SAP ERP telah dilaksanakan oleh perusahaan tersebut untuk mendukung operasi bisnis perusahaan. Namun dari beberapa implementasi SAP ERP pada ketiga perusahaan tersebut, perlu adanya pengetahuan tentang faktor-faktor kritis apa saja yang dapat mempengaruhi keberhasilan / performa implementasi SAP ERP pada masing-masing perusahaan.

Bradley (2004) mencatat fenomena keberhasilan implementasi ERP dipengaruhi oleh keberhasilan menyelesaikan faktor kritis keberhasilan (critical success factor). Pemilihan Faktor pada penelitian ini bersumber dari penelitian terdahulu yang jarang (tidak dominan) namun penting dan diduga memiliki pengaruh terhadap performa implementasi ERP, faktor-faktor yang akan diteliti yaitu Data Migrasi, dokumentasi sistem, transfer pengetahuan, pengujian sistem, dan integrasi interface.

Pada penelitian ini dilakukan studi dan observasi lapangan di perusahaan retail di Tangerang Selatan. Hasil dari penelitian ini diharapkan dapat memberikan informasi terkait faktor-faktor yang perlu diperhatikan untuk menunjang keberhasilan implementasi SAP ERP di masa mendatang.

Pada penelitian ini peneliti mengambil lima faktor yaitu Data Migrasi, dokumentasi sistem, transfer pengetahuan, pengujian sistem, dan integrasi dengan interface. Alasan pemilihan faktorfaktor tersebut dikarenakan faktor-faktor tersebut diduga mempunyai pengaruh terhadap performa implementasi SAP ERP. Pertanyaan yang akan di teliti dalam penelitian ini adalah :
1. Apakah Data Migrasi mempunyai pengaruh terhadap performa implementasi SAP ERP?
2. Apakah dokumentasi sistem mempunyai pengaruh terhadap performa implementasi SAP ERP?
3. Apakah transfer pengetahuan mempunyai 
terhadap implementasi SAP ERP?

4. Apakah pengujian sistem mempunyai pengaruh terhadap performa implementasi SAP ERP?

5. Apakah integrasi dengan interface mempunyai pengaruh terhadap performa implementasi SAP ERP?

\section{METODOLOGI}

Penelitian ini adalah penelitian studi kasus yang menggunakan data primer dan data sekunde. Data primer pada penelitian ini adalah wawancara dengan SAP Functional modul. Sedangkan Data sekunder yang digunakan pada penelitian ini berasal dari observasi lapangan dan dokumentasi implementasi proyek SAP ERP yang ada di industri retail di tangerangs Selatan.

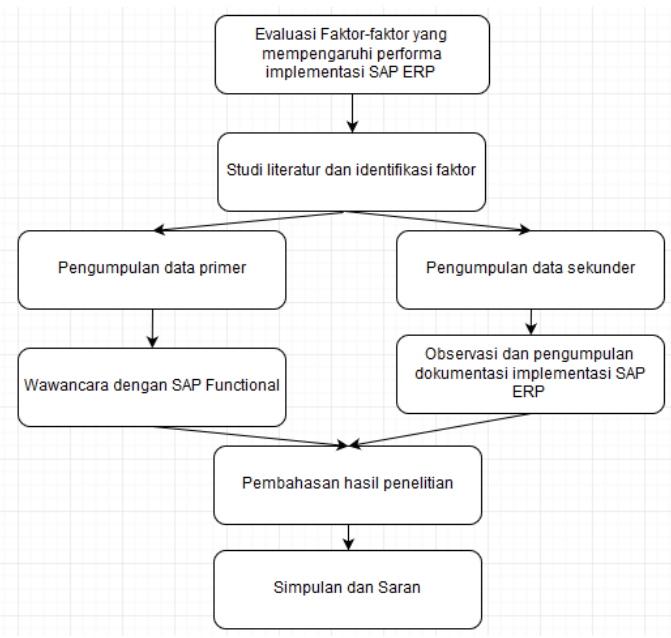

\section{LANDASAN TEORI}

Enterprise Resource Planning (ERP) adalah sistem lintas fungsional perusahaan yang didukung oleh modul software suite terintegrasi yang mendukung proses bisnis internal dari sebuah perusahaan, contoh penggunaan ERP untuk perusahaan manufaktur seperti pemrosesan data, melacak status penjualan, manajemen persediaan, manajemen pengiriman, faktur, manajemen bahan baku dan manajemen sumber daya manusia (O'Brien \& Marakas, 2011). Aplikasi enterprise yang ada saat ini diantaranya adalah SAP, Baan, PeopleSoft, Oracle, Microsoft Dynamic Axapta, Odoo, Adempiere, Openbravo, Odoo dan lain sebagainya.

\section{A. SAP}

SAP (Systems, Applications, and Products in Data Processing) didirikan pada tahun 1972 oleh lima mantan insinyur IBM, SAP telah sangat sukses dan secara global diakui sebagai solusi ERP yang menyediakan perencanaan sumber daya perusahaan kelas dunia, perangkat lunak ini sukses memberikan pengguna fitur seperti buku besar keuangan yang terintegrasi, penjualan, pembelian, dan sistem informasi manajemen, produk utama perusahaan SAP adalah SAP ERP. SAP R / 3 mencerminkan fungsi dimana "R" singkatan dari real-time dan jumlah 3 berhubungan dengan arsitektur client-server three-tier (lapisan database, lapisan aplikasi,dan lapisan presentasi) (Naeem \& Sheikh, 2011). 
Modul-modul yang terdapat dalam SAP diantaranya adalah : FICO (Finance Controlling), SD (Sales and Distribution), HR (Human Resources), PP (Production Planning), $\quad M M \quad$ (Material Management), QM (Quality Management), PM (Plant Maintenance), PS (Project System), ABAP (Advanced Business Application Programming), dan BASIS.

\section{B. ASAP Metodologi}

Pada pelaksanaan proyek implementasi SAP ERP, SAP memiliki metodologi sendiri yang dikembangkan agar berhasil dan efisien dalam pelaksanaan proyekproyek SAP yang dikenal dengan Accelerated SAP metodologi. Yosh Eisbart (2009) menjelaskan bahwa terdapat lima fase dalam ASAP roadmap yaitu : Project Preparation, Busines Blueprint, Realization, Final Preparation, Go Live \& Support, dan Continous Improvement.

\section{Identifikasi Faktor-faktor yang mempengaruhi Performa Implementasi SAP ERP}

Faktor-faktor yang diduga mempengaruhi performa implementasi SAP ERP yang akan di bahas dalam penelitian ini adalah :

\section{C.1 Data Migrasi}

Data migrasi merupakan proses transfer data bisnis (master data dan transaksi data) dari sistem aplikasi lain ke sistem SAP ERP, data migrasi terkadang disebut juga dengan transfer data, data migrasi berkaitan dengan legacy system dan legacy data dimana legacy system merupakan sistem aplikasi yang berisi data yang akan ditransfer sebelum migrasi disebut sebagai sistem warisan (atau sumber sistem) sedangkan legacy data merupakan data yang akan bermigrasi dari sistem warisan ke sistem SAP ERP dan disebut sebagai data warisan atau data sumber (Michael \& Johann, 2008).

C.2 Dokumentasi Sistem

Menururt Raja Gopalan (2010) keberhasilan dari implementasi ERP terletak pada kejelasan dokumentasi untuk menerapkan ERP dan pemilihan waktu yang tepat untuk pelaksanaan ERP. Oleh karena itu Zaitar Youssef \& Ouzarf Mohamed (2015) memasukan dokumentasi sistem sebagi faktor penting yang mempunyai resiko dalam implementasi SAP ERP.

L. Ganesh \& Arpita Mehta (2010) menjelaskan bahwa tidak ada implementasi ERP yang dapat sukses tanpa dokumentasi sistem (dokumentasi yang berkaitan dengan konfigurasi ERP dan training user), dan juga menyatakan terdapat pengaruh antara faktor teknologi yaitu dokumentasi sistem dengan keberhasilan implementasi ERP.

C.3 Transfer Pengetahuan

Darshana Sedera \& Guy G. Gable (2010) Knowledge Management Competency yang terdiri dari knowledge creation, 
knowledge retention, knowledge transfer, dan knowledge application mempunyai pengaruh terhadap Enterprise System Succes yang diukur melalui system quality, information quality, individual impact, dan organization impact.

Selanjutnya Guanghui Chen \& Yanzhi Lie (2013) menyatakan bahwa Transfer pengetahuan (Knowledge Transfer) mempunyai pengaruh positif terhadap performa implementasi ERP. Juga Dimitrios Maditinos et al. (2010) yang menyatakan bahwa dukungan konsultan dan user dalam transfer pengetahuan mempengaruhi efektifitas pelaksanaan sistem ERP.

\section{Pengujian Sistem}

L. Ganesh \& Arpita Mehta (2010) menjelaskan bahwa pengujian sistem adalah aktifitas penting yang mempunyai pengaruh terhadap keberhasilan implementasi ERP. Selanjutnya Zaitar Youssef \& Ouzarf Mohamed (2015) memasukan pengujian sistem sebagi faktor penting yang mempunyai resiko dalam implementasi SAP ERP.

\section{E. Integrasi Interface}

Menurut Colin White (2005) dalam Hanan \& Abdulrahman (2011), tingkatan dalam integrasi aplikasi interface adalah sebuah interface yang memberikan akses ke tiga jenis layanan termasuk bisnis, data, dan obyek yang disediakan oleh sistem khusus atau paket standar.

\section{F. Performa Implementasi ERP}

Wan Hsein Tsai et. al. (2010) melakukan penelitian tentang vendor sistem, konsultan, proyek manajemen, dengan performa implementasi sistem, yang terdiri dari kualitas sistem, kualitas informasi, kegunaan informasi, kepuasan pengguna, dampak terhadap individu, dampak terhadap organisasi yang dilaksanakan setelah implementasi sistem ERP, enam dimensi pengukuran tersebut diambil dari information success model yang disarankan oleh DeLone \& McLean yaitu Sistem Quality, Information Quality, Service Quality, Intention to Use, User Satisfaction, Net Benefit.

\section{G. Studi Literatur}

Studi literatur untuk identifikasi faktor-faktor yang mempengaruhi performa implementasi SAP ERP dapat di lihat melalui Tabel 1.:

Tabel 1. Tinjauan Literatur

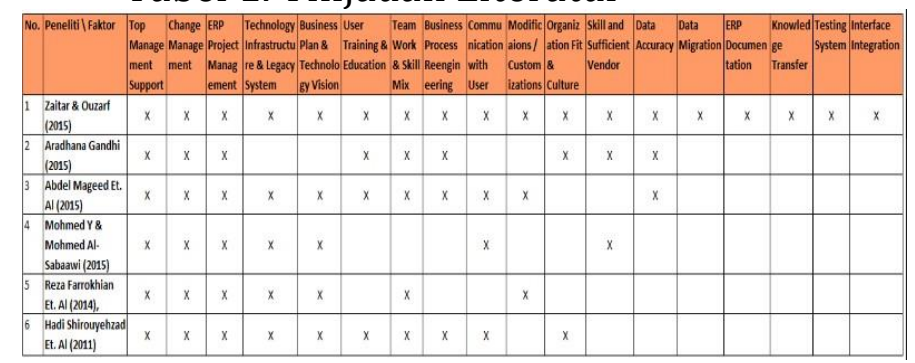

\section{PEMBAHASAN}

Jhon W. Cresswell (2009) menjelaskan prosedur pengumpulan data meliputi wawancara, observasi, dan pengumpulan dokumen-dokumen. Pada penelitian ini prosedur pengumpulan data dapat 
dijelaskan sebagai berikut :

\section{A. Wawancara}

Pada penelitian ini prosedur pengumpulan data dengan wawancara dilakukan kepada $S A P$ functional modul $P P Q M, S D, P M$, $M M, X I / P I$, dan FICO di Industri retail Tangerang Selatan.

Wawancara dilakukan dengan berbagai cara diantaranya face to face kepada Functional Modul SAP, wawancara dengan menggunakan telephone, dan wawancara melalui e-mail.

\section{B. Observasi}

Observasi yang dilakukan oleh peneliti adalah ikut serta dalam proyek implementasi SAP ERP baik itu proyek implementasi atau proyek support.

Dokumen-dokumen yang digunakan pada penelitian ini adalah dokumen implementasi SAP ERP yang ada di industri retail di Tangerag Selatan. Dokumendokumen tersebut yaitu dokumen business blueprint implementasi SAP ERP, dokumen data migration strategy, dokumen data migration cut over strategy, dokumen landscape server, dan dokumen pendukung lainnya.

\section{Verifiasi Data}

Pada penelitian kualitatif, instrumen utamanya adalah manusia oleh karena itu yang diperiksa adalah validitas datanya, untuk validitas data menurut Jhon Cressswell (2009) dapat menerapkan strategi berikut :

- Triangulation of Data : data akan dikumpulkan melalui berbagai sumber untuk menyertakan wawancara, observasi dan analisis dokumen.

- Member Chceking : informan akan mengecek seluruh proses analisis, dialog- dialog dengan interpretasi dari informan akan memastikan nilai kebenaran dari data. Member checking untuk menguji keabsahan data pada penelitian ini adalah dengan meminta persetujuan dari pimpinan proyek SAP ERP perusahaan retail yang berlokasi di Tangerang Selatan.

Jadi setelah penulis melakukan penelitian dengan menggunakan metode wawancara, observasi dan dokumentasi kemudian data hasil dari penelitian selanjutnya digabungkan sehingga saling melengkapi.

Hasil dan Pembahasan Gambaran Umum Perusahaan Perusahaan Retail di Tangerang Selatan Perusahaan ini implementasi SAP ERP dilakukan pada tahun 2010 dengan modul yang sudah di pasang yaitu Modul: FI (Financial), ME (Merchandise), dan RL (retail).

\section{Hasil Penelitian}

\section{- Data Migrasi}

Proses migrasi data di perusahaan ini yaitu memindahkan data dari legacy system yaitu Oracle ke SAP Retail. 


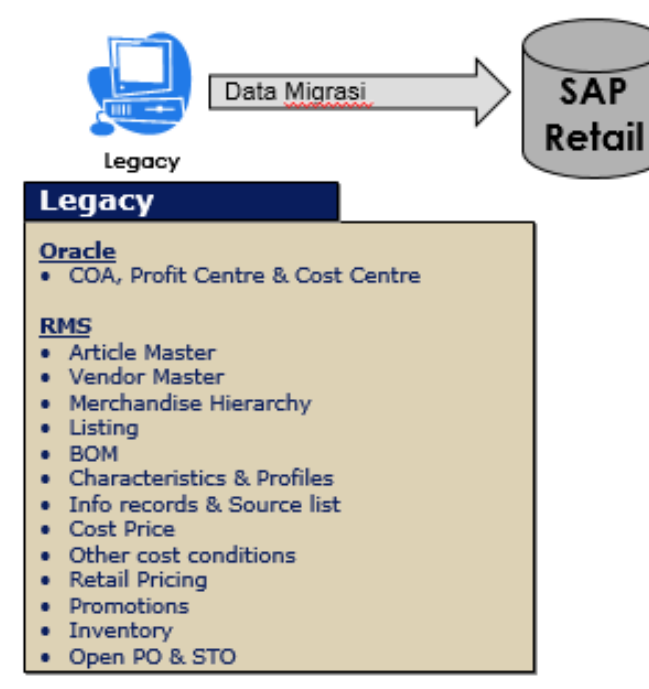

Gambar 3. Data Migrasi

Pada Gambar 3. data dari tim legacy system selanjutnya akan dilakukan pengecekan oleh tim SAP berdasarkan check list, lalu diserahkan kepada business process owner dan tim internal audit untuk verifikasi data. Data yang sudah diverifikasi akan di sign off oleh data owner sebagai tanda bahwa data sudah setuju dan siap untuk dipindahkan ke sistem SAP.

Selain itu, berdasarkan hasil wawancara dengan SAP PI/XI Developer dan SAP MM Functional yang menyatakan bahwa :

"Data migrasi sangat berpengaruh dalam implementasi SAP ERP karena sebagai initial data". (M. C. - SAP PI/XI Interface Developer)

"Data migrasi adalah salah satu faktor kunci dalam keberhasilan SAP ERP, data migrasi yang sukses di SAP adalah mutlak karena data yang di migrasi dari legacy system akan digunakan untuk proses proses selanjutnya baik dalam transaksi, reporting atupun kontrol" (A. J. - SAP MM Functional)

\section{E. Dokumentasi Sistem}

Berdasarkan observasi lapangan, dokumentasi sistem sudah diterapkan dengan baik malalui Knowlegde Management System (KMS) yang dibuat dengan software sharepoint. KMS yang dibuat menggunakan repository yang berisi knowledge terkait implementasi SAP ERP dan dapat diakses melalui portal website.

Hasil wawancara dengan SAP MM, dan SAP Operation memberikan pendapat tentang dokumentasi sistem diantaranya adalah :

"Dokumentasi sistem mempengaruhi performa implementasi SAP ERP, dokumentasi yang baik akan memudahkan dalam proses pemeliharaan dan support system selanjutnya. Karena sistem ERP akan digunakan dengan waktu yang panjang dan akan sering terjadi modifikasi / change request, apabila tidak ada dokumentasi dan key person yang tahu mengenai history tidak ada maka akan sulit untuk memenuhi perubahan selanjutnya ataupun troubleshoot yang terjadi”. (A. E. J. SAP MM Functional)

"Dokumentasi sangat dibutuhkan untuk perbaikan-perbaikan yang akan dilakukan kedepannya agar sistem erp selalu berkembang ke dalam proses yang lebih mudah”. (K. S. - SAP Operation) 


\section{F. Transfer Pengetahuan}

Berdasarkan observasi di lapangan, transfer pengetahuan dilakukan pada fase realisasi implementasi SAP ERP. Transfer pengetahuan untuk proyek support atau upgrade dilakukan sepanjang ada kebutuhan untuk transfer pengetahuan. Tim yang terlibat dalam transfer pengetahuan yaitu key user, end user, dan konsultan yang pelaksanaannya dijadwalkan pada fase realisasi implementasi SAP ERP. Transfer pengetahuan ini sebagai tempat untuk menceritakan update, issue, perubahan, dan peran dalam memakai sistem SAP ERP.

Didukung dengan hasil wawancara dengan SAP Operation dan SAP MM Functional berpendapat tentang pentingnya transfer pengetahuan :

"Transfer pengetahuan sangat mempengaruhi performa implementasi, terlebih kepada sifat dasar manusia yang memiliki pengetahuan yang berbeda beda. Jadi sharing knowlage harus dilakukan agar proses development berjalan dengan cepat." (A. F. H. - SAP ME Functional)

"Karena sistem yang digunakan berkepanjangan akan sering terjadi perubahan dan sering berganti person maintenance, proses transfer knowledge yang sukses akan membuahkan support yang lebih cepat dan lebih mudah untuk di improve ataupun di perbaiki apabila masih terdapat bug system, oleh karena itu transfer pengetahuan berpengaruh terhadap performa implementasi”. (A. E. J. - SAP MM Functional)

\section{G. Pengujian Sistem}

Berdasarkan dokumen system landscape strategy, Landscape server dibagi server menjadi tiga bagian utama yaitu server dengan nama EDI untuk server pengembangan dan pengujian yang teridri dari 050 (Sandbox), 100 (Config), 110 (ABAP), 300 (Unit Testing), 140 (User Acceptance Test), EQI sebagai server untuk quality assurance yang digunakan untuk pengujian terintegrasi, dan EPI adalah server production yang digunakan oleh end user untuk aktifitas sehari-hari.

Tahap pengujian ini sangat perlu dalam tahapan implementasi proyek SAP ERP dan sejalan dengan pendapat dari SAP MM Functional dan SAP FICO Functional yang menyatakan bahwa :

"Pengujian sistem mempengaruhi performa implementasi SAP ERP, karena pengujian sistem yang baik akan menghasilkan solusi yang tanpa cacat dan mudah dalam penggunaan dan pemeliharaan. Apabila solusi banyak bug dan tidak dapat diandalkan maka itu adalah hasil dari pengujian sistem yang buruk. Pengujian sistem harus baik dari perencanaan maupun 
pelaksanaan tekniksnya di lingkungan yang semirip mungkin dengan production system". (A. E. J. - SAP MM Functional)

"Pengujian sistem yang dilakukan oleh tim yang ahli/handal memberikan kecepatan, ketepatan, dan kepuasan pengguna dalam menerima hasil perubahan program"(S. B. - SAP FICO Functional)

\section{H. Integrasi Interface}

Berdasarkan dokumen
system landscape strategy,
perusahaan mempunyai sistem
aplikasi lain yang terdiri dari :
- Sistem aplikasi SAP ERP 6.0 yang digunakan untuk manajemen artikel / barang yang akan dijual ke gerai toko, manajemen pemenuhan kebutuhan dari permintaan toko, dan manajemen keuangan, serta pengaturan inventori.

- Aplikasi Back Office System (BOS) untuk mengelola pemesanan gerai sehari- hari, mengelola dan mengkoordinasi penambahan persediaan, serta mengelola masalah sehari-hari atas persediaan dan manajemen stok.

- Aplikasi TP-Linux yang digunakan untuk transaksi penjualan dan pencatatan kas di gerai toko

- Aplikasi VITAL untuk menangani pengelolaan gudang yang terpadu.



Gambar 6. Integrasi dengan interface

Pada Gambar 6. alur yang terjadi antara sistem SAP ERP yang di-interface-kan ke legacy system adalah sebagai berikut :

1) Sistem TS (Translation Database) pada diagram dapat dilihat sebagai Conversion $D B$ adalah database SQL Server akan menerima semua file dari SAP yang diperlukan oleh toko. Sistem TS ini berguna sebagai tool penerjemah agar data dapat dibaca dari sistem SAP ke legacy system.

2) Sistem TS akan mengkonversi file dalam format yang mudah dibaca BOS. UC4 akan menarik file sesuai jadwal yang sudah dibuat. UC4 merupakan aplikasi penjadwalan untuk proses interface antar aplikasi.

3) Setelah ada respon dari sistem toko selanjutnya disalin ke UC4 untuk dikonfirmasi.

4) File TP-Linux yang akan digunakan untuk penjualan diperoleh dari sistem TS

5) File yang akan digunakan oleh gudang juga dihasilkan oleh sistem TS 
Di industri ritel memiliki karakteristik ynag berbeda daripada industri lain oleh karena itu pada perusahaan ritel terdapat banyak aplikasi legacy system yang di interface kan ke aplikasi lain, hal ini senada dengan hasil wawancara dengan SAP MM Functional dan SAP Operation yang menyatakan :

"Interface adalah jembatan antara sistem SAP dengan sistem lainnya yang memerlukan keakuratan data untuk memastikan flow proses berjalan. Apabila interface gagal maka akan terdapat aliran yang terhenti dari proses ini dan akan menghambat operasional penggunaan sistem baik SAP maupun sistem lainnya, impact-nya adalah sistem akan gagal men-suport kebutuhan bisnis, oleh karena itu integrasi dengan interface sangat mempengaruhi performa implementasi SAP ERP”. (A. E. J. - SAP MM Functional)

"Integrasi Interface dengan
aplikasi legacy system sangat
dibutuhkan, karena dengan adanya
proses interface yang terintegrasi
dengan baik maka sistem erp kami
dapat berkomunikasi dengan sistem
lain". (K. S. - SAP Operation)

\section{Pelajaran (Lesseon Learned)}

Lesson learned yang dapat diambil dari hasil ini dapat dirinci sebagai berikut:

\section{Permasalahan :}

- Data yang dimigrasi mempunyai volume besar karena berasal dari berbagai sistem legacy, sehingga dibutuhkan tim tersendiri untuk mengurus data migrasi.

- KMS belum digunakan secara optimal, saat ini baru digunakan untuk menyimpan dokumen SAP terkait perubahan program

- SAP Solman baru digunakan untuk workflow transport perubahan program (Transport Request)

- Belum ada agenda dari divisi IT untuk sharing transfer pengetahuan kepada karyawan

- Karyawan dituntut belajar sendiri kepada karyawan yang lebih senior

- Perseroan memberikan training ke lembaga penyelenggara training SAP, sehingga membutuhkan budget untuk training karyawan

- Karyawan yang menjadi programmer legacy sudah pensiun, menyebabkan putusnya knowledge dari karyawan lama ke karyawan pengganti.

- Server untuk pengujian yaitu server quality assurance mempunyai data tidak mirip dengan server production, sehingga menyulitkan proses pengujian

- Karyawan yang ditugaskan untuk menangani aplikasi legacy dirangkap untuk menangani aplikasi lain, sehingga karyawan kurang fokus dalam menangani suatu permasalahan

\section{J. Kondisi Sebelum dan Sesudah Implementasi SAP ERP}

Agar dapat melihat manfaat dan dampak implementasi SAP ERP terhadap perusahaan, maka pada bagian ini penulis meninjau kondisi dimana perusahaan sebelum dan sesudah implementasi SAP ERP.

- Sebelum implementasi SAP FICO, Perseroan menggunakan Oracle 
Finance sehingga memerlukan aplikasi interface sebagai penghubung

- Reporting di Oracle Finance cenderung kaku dan kurang memfasilitasi kebutuhan Perseroan

- Tim IT melakukan recovery data interface setiap hari dari sisi SAP

- Aplikasi legacy yang terpisah-pisah sehingga tidak terintegrasi

- Terdapat double posting (transaksi) dalam entry data

\section{K. Kondisi sesudah} implementasi SAP ERP

Kondisi Perseroan setelah implementasi ERP, manfaat yang dirasakan Perseroan adalah mempunyai keunggulan kompetitif dibandingkan perusahaan lain yang belum implementasi SAP ERP, yang dapat dijelaskan sebagai berikut:

- Pengurangan aktifitas recovery data di SAP yang berasal dari interface legacy system

- Report yang dikeluarkan SAP sudah memenuhi kebutuhan user

- Proses tutup buku (closing) finance dan accounting pada akhir bulan dan akhir tahun lebih terorganisir dengan baik

- Menghilangkan aktifitas yang tidak bernilai tambah seperti data entry ganda

- Menyediakan interface aplikasi yang sederhana dan mudah digunakan.

- SAP modul dan aplikasi legacy melalui interface sudah terintegrasi

- Memberikan solusi terintegrasi atas kelemahan sistem saat ini.

- Memudahkan pemenuhan persediaan di gerai toko dan gudang

- Memberikan layanan yang cepat ke gerai toko dan gudang

\section{Rekomendasi Implementasi Selanjutnya}

Berdasarkan uraian permasalahan dan faktor-faktor non teknis selain faktor utama yang di teliti yaitu data migrasi, dokumentasi sistem, transfer pengetahuan, pengujian sistem, dan integrasi interface. Maka penulis merekomendasikan aktifitas yang perlu diperhatikan dalam implementasi proyek SAP ERP di masa mendatang adalah sebagai berikut :

- Membuat tim terpisah untuk menangani data migrasi.

- Mengikuti standar SAP dalam aktifitas data migrasi.

- Memberikan sosialisasi kepada karyawan sebelum proyek dimulai.

- Membuat program khusus untuk akurasi persediaan gerai toko.

- Memberikan fasilitas ruangan terpisah untuk konsultan / vendor selama proyek berjalan.

- Memilih manajer proyek yang berpengalaman dalam bidang SAP ERP dan mengerti bisnis retail.

- Copy data dari server production ke server quality assurance setiap bulan sekali.

- Membuat agenda terkait aktifitas transfer pengetahuan di Divisi Teknologi Informasi.

- Memberikan transfer pengetahuan dari karyawan yang akan pensiun ke karyawan pengganti.

- Menempatkan konsultan WMS (Werehouse Management System) yang mempunyai kompetensi dibidangnya.

- Membuat tim internal untuk menangani teknis SAP yaitu 
merekrut Abaper dan Basis dari Indonesia.

- Mengikuti standar SAP dalam aktifitas pengujian sistem SAP ERP.

- Mengoptimalkan KMS dalam mengumpulkan knowledge dari semua karyawan dan konsultan/vendor.

- Memberikan penugasan kepada karyawan sesuai dengan keterampilan yang dimiliki.

- Memonitor dan mengawasi progress update dari issue-issue permasalahan SAP dengan vendor

- Mengoptimalkan KMS dan Solman dalam mengumpulkan knowledge dari semua karyawan dan konsultan/vendor.

\section{SIMPULAN}

Hasil wawancara, dokumen implementasi, dan observasi di lapangan dapat disimpulkan bahwa faktor data migrasi, dokumentasi sistem, transfer pengetahuan,

Pengujian sistem, dan integrasi dengan interface sangat penting dan berpengaruh dalam implementasi SAP ERP.

1. Data migrasi sudah dilakukan dengan pendekatan strategi data migrasi di perusahaan retail di Tangerang Selatan.

2. Dokumentasi sistem sudah dibuatkan portal Knowledge Management System (KMS), dan dokumentasi sistem ditempatkan di file sharing server.
3. Transfer pengetahuan di perusahaan retail di Tangerang Selatan sudah melibatkan konsultan, key user, dan end user.

4. Pengujian sistem sudah dilakukan di server development, quality assurance, dan preproduction di perusahaan retail di Tangerang Selatan.

5. Integrasi dengan interface di perusahaan retail di Tangerang Selatan tersebut memiliki aplikasi legacy system.

Berdasarkan hasil wawancara dan observasi ini diharapkan faktor data migrasi, dokumentasi sistem, transfer pengetahuan, pengujian sistem, dan integrasi interface agar lebih difokuskan untuk peningkatan performa implementasi SAP ERP pada proyek-proyek SAP ERP. Penelitian lebih lanjut disarankan untuk memilih faktor-faktor lain seperti dari sisi manajemen proyek, konsultan, keterlibatan user, komunikasi, dan dukungan manajemen puncak yang dapat mempengaruhi keberhasilan SAP ERP. 


\section{DAFTAR PUSTAKA}

Abdelmageed, Elsadek, Abdelrazek. (2015). Strategic Planning for Successful ERP Implementation. Proceedings of 7 th Annual American Business Research Conference ISBN: 978-1-922069-79-5. New York USA

Aradhana Gandhi. (2015). Critical Success Factors in ERP Implementation and their interrelationship using TISM and MICMAC Analysis. Indian Journal of Science and Technology, Vol 8(S6), 138-150.

Hadi, S., Reza, D., Mostafa, B. (2011). The FMEA Approach to identification of Critical Failure Factors in ERP Implementation. International Business Research Vol. 4, No. 3; July 2011.

Mohmed Y. Mohmed, A. S. (2015). Critical Success Factors for Enterprise Resources Planing Implementation Success. International Journal of Advances in Engineering \& Technology ISSN: 22311963

Reza, F., Faezah, S., Yousef, G., Sayed, M. (2014). A Structural Equation Model for Identifying Critical SuccessFactors of Implementing ERP in Iranian,Kalleh Food ProductsCompany. Proceedings of the 2014 International Conference on Industrial Engineering and Operations Management. Bali Indonesia

Zaitar Youssef, Ouzarf Mohamed. (2015). Appliying Ishikawa Approach for Modeling ERP Risks Effects. Journal of Theoretical and Applied Information Technology Vol.71 No.1. ISSN: 1992-8645.

PT. Hero Supermarket Tbk. (2010). Business Blueprint Implementasi SAP. Jakarta

Naeem, A. Sheikh, M. T. (2011). SAP ERP Financials : Configuration and Design. Galileo Press: Bonn Boston.

Bradley, J. (2004). Enterprise Resource Planning Success: a management theory approach to critical success factors. California: ProQuest Information and Learning Company.

Yosh Eisbart. (2009). Outsourcing SAP Operations. Galileo Press Gmbh

Michael, W., Johann, G., (2008). Migrating your SAP. Galileo Press Gmbh

Raja Gopalan. (2010). Process Documentation A Pre-Requisite For ERP Implementation. Knowledge Management Series Volume 1 Issue 2. G. Balu Associates India.

L. Ganesh, Arpita Mehta. (2010). Critical Success Factors For Successful Enterprise Resource Planning Implementation At Indian Smes. International Journal of Business, Management and Social Sciences Vol. 1, No. 1, 2010, pp. 65-78.

Sedera, Darshana \& Gable, Guy (2010). Knowledge management competence for Enterprise System success. The Journal of Strategic Information Systems,19 (4), pp. $296-306$. 
Guanghui Chen \& Yanzhi Lie. (2013). Study on Knowledge Transfer on ERP Implementation Performance from Inherent Angle of Enterprise. Information Technology Journal 12 (23): 7555-7561,2013

Hanan, A. A. T., Abdulrahman, A. M. (2011). Reasons for failure of ERP System Enterprise Application Integration. College of Computer and Information Sciences King Saud University Saudi Arabia.

Wen-Hsien Tsai. (2010). A Study of the Impact of Business Process on the ERP System Effectiveness. International Journal of Businessand Management

Jhon W. Cresswell. (2009). Research Design - Qualitative, Quantitative, and Mixed Methods Approaches. California : SAGE Publications Inc 